\title{
Les réseaux socialistes dans le Morbihan
}

Journée d'étude organisée à l'université de Bretagne-Sud par François Prigent, doctorant, CERHIO UMR 5258

\section{François Ploux}

\section{(2) OpenEdition \\ 1 Journals}

Édition électronique

URL : http://journals.openedition.org/abpo/349

DOI : $10.4000 /$ abpo.349

ISBN : 978-2-7535-1509-3

ISSN : $2108-6443$

\section{Éditeur}

Presses universitaires de Rennes

\section{Édition imprimée}

Date de publication : 30 mars 2008

Pagination : 13-14

ISBN : 978-2-7535-0653-4

ISSN : 0399-0826

\section{Référence électronique}

François Ploux, "Les réseaux socialistes dans le Morbihan », Annales de Bretagne et des Pays de l'Ouest [En ligne], 115-1 | 2008, mis en ligne le 30 mars 2008, consulté le 23 septembre 2020. URL : http:// journals.openedition.org/abpo/349; DOI : https://doi.org/10.4000/abpo.349

Ce document a été généré automatiquement le 23 septembre 2020.

(c) Presses universitaires de Rennes 


\title{
Les réseaux socialistes dans le Morbihan
}

\author{
Journée d'étude organisée à l'université de Bretagne-Sud par François
} Prigent, doctorant, CERHIO UMR 5258

\section{François Ploux}

\section{NOTE DE L'ÉDITEUR}

Nous publions ici un compte rendu fait par François Ploux de la dernière journée d'étude à laquelle avait participé François Chappé, le 29 septembre 2007, à l'université de Bretagne sud.

1 Le 29 septembre 2007 s'est tenu à l'université de Bretagne-Sud (Lorient) une journée d'étude consacrée aux réseaux socialistes dans le Morbihan, des années 1930 aux années 1980. François Prigent, doctorant à l'université de Rennes II, où il prépare une thèse sur le socialisme dans l'Ouest, était le maître d'œuvre de cette manifestation. L'objectif fixé aux intervenants consistait à étudier l'implantation de la SFIO et du PS dans le département en s'aidant d'outils théoriques qu'a expérimentés l'historiographie récente du politique: la prosopographie, la mise au jour des trajectoires sociales des élus, l'étude de la structuration et du fonctionnement des réseaux...

2 François Chappé, maître de conférences à l'université de Bretagne-Sud, inaugurait cette journée par un rapide et brillant exposé liminaire sur les enjeux de l'histoire politique, qui sera hélas sa dernière intervention publique au «Paquebot », où il avait tant aimé enseigner. Il nous a en effet quitté le 18 novembre dernier. Très affecté physiquement par la maladie contre laquelle il luttait depuis trois ans, il avait tenu à participer à cette journée, où furent abordées toute une série de questions qui le passionnaient, en tant qu'historien bien sûr, mais aussi en tant que citoyen très impliqué dans la vie intellectuelle locale.

3 Les deux premières communications étaient centrées sur la question des trajectoires individuelles de quelques figures majeures du socialisme morbihannais. Jacques Girault, 
professeur à l'université de Paris XIII, s'est attaché à l'itinéraire de Joseph Rollo, secrétaire du Syndicat national des instituteurs, qui mourra en déportation. Né à Vannes, membre du Parti communiste, puis, après son exclusion en 1931, de la SFIO, Rollo siégea au bureau national du SNI à partir de 1935. Il y joua le rôle d'un ardent défenseur de la laïcité. La seconde intervention, présentée par Gilles Morin (docteur en histoire contemporaine) portait sur les trajectoires comparées des parlementaires lorientais Louis L'Hévéder élu à partir de 1930 et Jean Le Coutaller élu à partir de 1945.

lexposé de François Prigent c'est la question des réseaux socialistes qui est abordée de front. Il s'est intéressé plus particulièrement aux réseaux « seconds ", dont l'importance est habituellement sous-estimée (à tort, car, ces réseaux, dont l'assise géographique correspond au canton, sont en position intermédiaire entre, d'une part les instances dirigeantes du parti, d'autre part les militants et les électeurs). L'analyse proposée du groupe des conseillers généraux socialistes est très riche et stimulante. Elle met notamment en évidence l'importance des milieux enseignants : enseignants du supérieur dans les années 1930, instituteurs à la Libération, enseignants du secondaire à compter des années 1980. François Prigent s'est aussi efforcé, et de manière très convaincante, de montrer l'imbrication des réseaux proprement politiques et des réseaux syndicaux, associatifs ou encore intellectuels, avant de conclure par une typologie de l'implantation du socialisme dans le Morbihan. L'exposé de Christophe Rivière, doctorant à l'université de Bretagne Occidentale, portait sur l'implantation socialiste dans l'arrondisement de Pontivy au cours des années 1930. À la faveur de la crise du monde rural, et dans un contexte d'intense mobilisation paysanne, les militants socialistes parviennent à diffuser leurs idées dans un territoire autrefois dominé par les conservateurs et où les radiaux s'étaient implantés durant l'entre-deuxguerres. Christophe Rivière met en évidence l'action du syndicalisme agraire, et le rôle des instituteurs au sein de ces formations, qui dénoncent l'emprise de la grande propriété et la montée du fascisme (incarné ici par le dorgérisme). Ces mobilisations s'avèrent semble-t-il des matrices des réseaux d'élus socialistes à la Libération.

5 David Bensoussan, docteur en histoire et professeur au lycée Châteaubriand, s'est intéressé dans son intervention à l'image du socialiste et aux représentations du socialisme dans le discours des droites morbihannaises au cours des années 1920 et 1930. La dénonciation du péril socialiste vise en particulier à discréditer les radicaux, qui mènent la lutte contre le bloc agraire (défini comme l'alliance de l'aristocratie foncière, du clergé et de la paysannerie conservatrice). La démocratie chrétienne aura, elle, recours à la rhétorique antisocialiste pour tenter de détacher les républicains modérés de la gauche socialiste. Dans le discours des droites bretonnes, le socialisme apparaît comme une doctrine répulsive. Par conséquent, observe David Bensoussan, le regard des droites morbihannaises sur le socialisme en dit plus sur ce que sont les droites que sur la réalité de la SFIO dans le département. Dans les années 1930, le discours s'articule autour de la dénonciation de quelques figures, en particulier celle du fonctionnaire, incarnation d'une bureaucratie parasitaire (vision inversée du rôle du militant instituteur).

6 La communication de Vincent Porhel, maître de conférences à l'IUFM de Lyon, portait sur «La CFDT en terre Cégétiste: représentations croisées autour des forges d'Hennebont. 1952-1966». Dans le cadre d'un mouvement social puissant, il s'agissait de présenter l'imbrication des réseaux syndicaux et des milieux partisans pour les différentes familles politiques communiste, socialiste et démocrate-chrétienne. 
7 La discussion finale est animée par Jean-Noël Retière (université de Nantes), avant que François Prigent ne reprenne la parole pour faire le bilan de la journée. Les actes de la journée seront publiés début 2008 dans le prochain numéro de Recherche Socialiste, revue de l'Office Universitaire de Recherches sur le Socialisme (OURS), partenaire avec le CERHIO et le SOLITO du projet. Un compte rendu détaillé des axes des différentes interventions est d'ailleurs disponible sur le site internet de l'OURS.

\section{AUTEUR}

FRANÇOIS PLOUX 